\title{
Emerging hiring strategies to manage talent crisis in newly graduate engineers - A case of benefits, outcomes and implications
}

\author{
Sufia Rehman \\ Research Scholar, Dept. of Commerce \& Management, Integral University, Lucknow, Uttar Pradesh, India
}

*Corresponding Author:

Email: suffo4u2@gmail.com

\begin{abstract}
In the present complex corporate environment existing globally, recruitment has evolved as the most challenging human resources (HR) function across all industries. It has becoming for organizations to invest in their recruitment strategies. Steered by developments in technology the old recruitment strategies are being remodeled and redesigned. Recruiters are fast adopting latest hiring strategies for talent hunting in order to manage the talent crisis that exists in the present influx of graduate engineers entering the job market every year. Merely posting adverts in newspapers or visiting education institutions for hiring new graduate engineers is not sufficient to meet the existing demands for talent. Internet which has not only affected the life of common people but it has also transpired as a vital talent acquiring tool for the contemporary HR Manager. The amazing benefits like acceptance $\&$ popularity of Internet and Social Media Sites, short response time, positive return on investment added with good competitive edge and ease of use have all convinced the recruiters to use them not only for effective branding but also compelled them to use these new strategies for hunting for new talent and recruitment. Nowadays more or less every fresh graduate / professional has a Social Media account which makes it as huge resource of talent pool for the recruiters. Professional networking offering a good platform is being used as a hiring tool very prominently and impacting both the recruiters and new graduate engineer job aspirants. The author in the study has analyzed the emerging trends in hiring strategies, their effectiveness for the employers for talent management and the influence they have on the new graduate engineer job aspirants. The study highlights benefits of new hiring strategies over traditional methods. Their outcome and implications and their capacity to turn the job opportunity into a success of a failure for the new graduate engineer job aspirants.
\end{abstract}

Keywords: Human Resource Management, Talent Crisis, Recruitment Strategies, Internet, Online job portals, Social Media Networks, Employers, New Graduate Engineer Job aspirants.

\section{Introduction}

"Change is the only constant"

Today, the HR profession stands at a critical intersection. Irrespective of the Industry sectors, there is an increase in complexities in the entire corporate world and the Human Resource department in almost every organization is functioning at a grueling pace. It is struggling to cope with new challenges, particularly of talent management at entry level jobs meant for new graduate engineers. Hunting for talent and new talent pool, for entry level technical positions distinctly for new graduate engineers, calls for strategies which requires more than publishing newspaper advertisements or visiting educational institutions for the purpose of campus recruitment. The competition has forced the employers to use the recruitment strategies which are more stimulating and exciting. Traditional strategies are being dramatically transformed with the combination of novel tools and Internet based technology and communication channels, creating a revolution in the recruitment arena. The entire recruitment process has been taken over by something which started as an accessory to conventional paper based tedious process. Today the entire recruitment cycle has fully become digital, each step starting from advertising about vacancies, job description, inviting resumes and applications, screening, selection process, final offers to investigating the candidate's back ground on the basis of web habits and browsing history etc. is possible through online means. The cycle is successful with the ultimate final joining of the right talented candidate who can contribute in achieving the organisation's vision.

Recruiting via the use of internet as a tool started during the last decade of the twentieth century, triggering in a comprehensive makeover to corporate hiring. It was referred to as "recruiting revolution" and forecasted that the recruitment industry has its "future on the net". This was due of the major advantages it brought for the recruiters. Internet has hitherto impacted upon and the basic essence of the traditional recruitment process, empowering not only the corporate and vendors but also the young job aspirants to become tech-savvy and communicative. In fact today the employers are compelled to vigorously and positively promote themselves by instituting a well-executable recruitment exercise, in pursuit of right talent and constructive recruiting decisions which are effective in terms of both time and money. The modern recruiter are tempted to embrace Online recruitment techniques using new technologies because of the many benefits they give such as enhanced speed of candidates mapping with the live vacancies .

Internet \& Social media has dynamically influenced the world at large. Almost every professional / young job aspirant is aware of Social networking websites or Social media and immediately relate to Facebook, Twitter, 
Linked. With every third person having a Facebook account, having digital footprints is quite prevalent. Social media apart from networking also provides abundant opportunities as well. It has brought in the concept of social media recruiting where hiring of talent or right candidates via the use of social platforms as talent database. Many a times this social platform is used in search for information on passive candidate and job posting via social media profiles, blogs, and online communities as a talent pool for sourcing talent. On the social platform both the recruiter as well as young job aspirants share employment details within their online social networks. This has opened up completely new avenues for both the young job aspirants, but also for the employer through easy access to a huge pool of active and passive young job seekers. For both the parties it is a matter of just hitting the right button. The new hiring strategies are gaining high appreciation by the human resource teams of reputed organizations to the extent that they are fast remodeling incorporating them into their comprehensive business strategy. The use of new techniques for hunting for the right talent is evidently becoming quite popular and organizations very proficiently float a wide net through social websites while simultaneously using them to trim their search for distinct requirements. Some of them have in due course been able to develop hiring strategies to almost perfect levels. The emerging new hiring strategies are handy not only in searching for suitable candidates for senior level profiles but are also quite effective while hunting candidates for entry level technical positions where new graduate engineers are required. Social networking websites like Facebook, Twitter, and Linked-In are utilized by the employers for conducting reference / background check of the potential entry level candidates and they have also turned out as useful job search tools for the new graduate engineer job aspirants as well.

\section{Objective of the Study}

1. One of the main objective is to study the emerging hiring strategies for effective recruitment of New Graduate Engineers at entry level technical positions, with special reference to selected districts of Uttar Pradesh.

2. To study the outlook of Recruiters on the efficacy of new hiring techniques as recruitment strategy for talent management at entry level.

3. To study the outlook of a New Graduate Engineer Job Aspirants the effectiveness of recruitment through new hiring techniques.

4. To study the benefits, outcomes and implications for both the Recruiters and New Graduate Engineer Job Aspirants.

\section{Literature Review}

Changing techniques for searching for talent: There are a vast range of "Traditional Methods" for searching and reaching out for prospective job candidates. As Joos
(2008) puts it, these techniques depend on the supposed 'spray and pray' method where announcement or applications are sent out ('sprayed') in large numbers and both employers and job aspirants wait ('pray') for feedback. The emergence of new technological tools like the internet and online social media more specifically have led the organizations to adopt new approaches for talent hunting as well as recruitment. Internet and Online Social Networking being a new phenomenon and hiring strategies which employ online job portals, social media and mobile technology is relatively a new research area. There is a limited volume of empirical literature for the topic as it is a relatively new subject area. The author approached the topic in two distinct steps, with first the study into the old conventional techniques of recruitment followed by the evolution to modern methods of recruitment. Another challenge was to identify the right method to source information for this topic. The sources were selected based on to their similarity to this rather new and exploratory topic. The author started with the keywords like "Social media", "E-recruiting", "Online recruiting", "new hiring techniques " and " emerging hiring strategies" etc. and results gave directions for the road forward. Smartphones, Facebook, Linked-In and other Social networking sites like Twitter and WhatsApp etc. are the product of the $21^{\text {st }}$ century, therefore in reference to this paper, researches published before the year 2000 were found not very applicable.

The expeditious popularity of Social media has influenced quite a number of human resource practices (Bingham \& Davison, 2002). Resulting in an $85 \%$ increase in recruiting activities via social media since 2007 (Salmen, 2012). The Jobvit's recruiting survey (2012) says that over $73 \%$ of companies have amalgamated this new phenomena of online social media networking as portion of their comprehensive recruitment strategy.

Hiring trends of any industry can be fully comprehended by taking into account the perceptions of both the recruiters and the individuals seeking job in that industry. With this as the main criteria, we are analyzing the new hiring strategies, their influence, outcome, benefits and implications from the view point of both the recruiters as well as the new graduate engineer job aspirants.

\section{Recruiter's perception of the new hiring strategies}

Interesting observations have been made by different researchers about the new trends in recruitment strategies from the perspective of the recruiters.

1. High paced rise in the use of Online Job Portals and Social Media. (Parry \& Tyson 2008), has led the modern recruiter to dramatically shift from using traditional methods of sourcing candidates by placing job advertisements through newspaper \& professional journals, towards the Internet.

2. Survey by Jobvite on Social Recruiting ( 2012 ) says that up to $92 \%$ of employers in the U.S. have started 
using social media networks to screen and recruit prospective job aspirants. This was only $78 \%$ about 5 years ago. A good number of recruiters also use more professional site like Linked-In. Almost two thirds use Facebook for recruitment and more than $50 \%$ use Twitter for new talent search.

3. A study by Workforce (2000) announces that because of the elimination of intermediaries in the new hiring techniques and the companies who deploy them have a reduced their recruitment cycle by up to $30 \%$ a compared to those companies who are still using other traditional recruitment strategies.

4. Researchers like Melanthious et al. (2015) appreciate the positive aspects of these new recruitment strategies, asserting that they help recruiters in searching, locating and attracting target applicant along with the providing ease of administering background checks on new recruits. Further on despite the many advantages of the new strategies yet some employers still abstain from using these new recruitment tools.

5. Compton et al. (2009) and Arlington et al. (2004) say that these new strategies of recruitment can give direct competitive advantage as they provide easy access to national as well as international talent pool making it a big attraction for the recruiters. Many recruiters have already started using the various new age recruitment strategies effectively.

6. Kilpatrick (2013) in his research however questions the effectiveness of these new age recruitment strategies stating the lack of tools and systems which can help to develop the employers' judgment or assessment. Social Media as recruitment tool also does not have arrangements and methods for relationship management with numerous clients and aspirants.

7. In one more research Reiners \& Alexander (2013) insist that in order to achieve actual recruitment success via these new hiring strategies like job portals \& social media, it is very crucial that not only the recruiters but also the young job aspirants, across the world, should be aware of social rules governing both the content, style and use of their social profiles posted by them.

8. However researchers like Gallagher and O'Leary (2011) emphasize on the ability of the new hiring strategies like job portals \& social networking sites which have excellent multimedia tools and provide a two way communication platform. This allows the recruiters to reach both passive as well active job seekers effectively. The recruiters have the advantage of using the social media sites for building relations and for enlightening the young job aspirants about the Company, brand, culture, vacant positions, job profiles etc.

9. In their study Davison, Marathi and Bing (2011) contemplate that the new hiring strategies like
Social Media can be valuable 'friends' for HR, but if not utilized carefully there are big chances that they can turn into dangerous 'foes' and create problems.

The perspective of new graduate engineer job aspirants on the new hiring strategies

1. One of the researchers Plummer et al. (2009) point out that the new hiring strategies using online resources is beneficial not only for the recruiters, but also hold advantages for new graduate engineer job seekers .One of them being that these strategies have made the recruitment process more transparent and responsive. Now the new graduate engineer job aspirants can access influential referees and gather pertinent information about the job profile and the organization thus gaining vital inputs on preparations for the initial job screening process.

2. HR firm, Kelly Services (2012) in their report brings focus to the fact that the popularity of Social Media among the new generation has grown at a tremendous speed. Their report states that even in countries like India every $5^{\text {th }}$ new graduate engineer job aspirant makes use of social networking sites during their search for jobs.

3. Yet another recruiting consultant Ma Foi -Randstad states (2012) that in India about $87 \%$ of new graduate engineer job aspirants access the Internet to collect relevant information about the organization brand and its work culture.

4. Narvey (2009) in their study state one of the most prominent and also the biggest benefits of New hiring strategies is free participation and engagement with larger communities. Recruitment has become a very proactive and interesting process for both the recruiters as well as the young technical job aspirant who are continuously Introducing, Inviting, Sharing and referring each other through social networking platform. (Eel, Werner, Du Plessis, Fazey, Erwee, Pillay, Mackinnon, Millett \& Wordsworth 2012).

\section{Hiring strategies used by recruiters: Traditional vs New}

Recruiters are using various hiring strategies to map the right talent for the right jobs. Table given in Annexure 1 contains a list of some traditional and new recruitment strategies being used by the organizations as well as the new graduate engineer job aspirants in their respective searches.

\section{Research Design}

An exploratory research was carried out to understand the effect of new hiring strategies adopted by the Human Resource Department of various companies and also to understand their relevance for New Graduate Engineer Job Aspirants. 
Sample Design: The study covers companies across sectors functioning mainly in selected cities of Northern India's state of Uttar Pradesh, (including cities of NOIDA, Allahabad, Ghaziabad, Lucknow). Respondents have been chosen using 'Random Sampling Technique'

Data used: This study uses both Secondary as well as Primary Data.

i. Secondary Data: The major source of Secondary data have been $O$ nline books, articles in journals and company websites.

ii. Primary Data: Primary data have been collected through the "Survey Method" with the help of structured questionnaires. Two kinds of questionnaires were developed: One for the recruiter and second for the fresh Graduate job aspirants.

Sample Size: For the purpose of this study 7 companies across industries functioning in selected cities of the state of Uttar Pradesh, India were selected randomly. The two Questionnaires were given to 100 HR Managers and 100 Newly Graduate Engineer Job Aspirants (applied in or already selected in the particular company) as respondents. The questionnaires were personally administered in the form of interview and the respondents were requested for support and thanked for their cooperation in answering the survey questions.

\section{Details listed in Appendix 2}

Analysis technique: The responses from both the questionnaires were analyzed using graphical representations, bar diagrams and pie charts to draw out the conclusions for the study.

Here it is very relevent to point out that almost no emphasis was given to demographics like gender and age of respondents.

\section{Findings and Discussions}

Based on the analysis of the study through the graphs, it was discovered that the new Hiring Strategies are fast becoming popular. Bothe the recruiters as well as job aspirants are not only aware of existence of these new method of hiring but also being frequently used. They are picking up ubiquity for searching of new talented young Graduate Engineer job aspirants. Recruitments through the use of new hiring strategies like through Online job portals, Social Media, Smart phone Apps / Mobile Technology, Employee Referral, Campus events and Technical Competitions have come out as the most prominently utilized systems for enlisting .

1. The responses to survey questionnaire clearly show that the primary reasons behind the choice to use new recruitment strategies were, rapidly changing worldwide business situation and high rate of innovative progressions in technology. Surviving testing competition and identifying new talent source pool are other equally important drivers for selecting new strategies.

2. Recruiters are promptly utilizing the new hiring strategies to not only to save Time but also to save cost.

3. The new graduate engineer job aspirants likewise have a positive picture about the organization who are utilizing the New Hiring methods.

4. The new graduate engineer job aspirants too very comfortable and tech-savvy and therefor now expect the recruitment process to be transparent and less time consuming. They want the direct attention of the recruiters and fast response time.

\section{The Outcome}

New Hiring Strategies have opened doors to a radical new world for both the recruiters as well as the new graduate engineer job aspirants alike. Loaded with large number of benefits and advantages some more clear and noticeable, while others, however more subtle yet are very critical.

\section{Benefits of using new hiring strategies for the recruiters}

1. Enhancement In Process Administration: The most obvious benefit that the selection of new Hiring methodologies is Operational Improvement in recruitment process administration. When compared to customary, paper-based hiring these new strategies encourage a more standardized, controlled and streamlined approach all through each stage of the recruitment procedure. This is due to the move from manual to computerization resulting in a snappier pivot time.

2. Ease of use for Corporate Branding: The positive effects of the new Hiring techniques have outperformed the core domains of HR and fortify the organization in different ways, too. In an era of image and reputation, the new Hiring Strategies can shape an essential segment of an overall brand administration system at almost no cost. The enhancement in brand awareness is an intangible yet crucial variable for winning in the present dynamic and high facilitated aggressive corporate world. The recruiter can every day effectively construct and build upon the corporate brand even before actual job posting. Whenever they talk about the normal working day, special office occasions or organization culture on web-based networking media they are pulling in a line of energized talented and gifted youths intrigued by comparable worklife. Doing indirect corporate branding.

3. Visibly less time consuming: The new Hiring Strategies are less time consuming because of smaller recruitment cycle. The Screening procedure, for example, sorting, arranging, coding, recording, routing and recovering of applications which were very tedious and laborious for the recruiters are now automated thus making the recruitment cycle time 
much shorted .

4. Cost effective: The technology based new Hiring Strategies not just enhance the proficiency of the recruitment procedure but also lead to yet another major advantage that is making the whole recruitment procedure significantly cost effective . This point is exceptionally valuable for considerably smaller organizations having low recruitment budget. Despite the fact that there is a critical cost engaged with creating and overseeing a full-scale recruitment framework on corporate website, the recruitment costs have reduced significantly after the selection of these new hiring procedures and frameworks as indicated by the recent industry studies. Web-based social networking sites are generally available free of cost. The recruiter can use other available online resources for support in filtering and cross verifying the candidate information.

5. Global spread and access to International talent: Almost every demographic group has an online presence today making it a reason for giving preference and utilizing the new recruitment system. This point makes for the recruiter the accessible effective range of reach for prospective aspirants is considerably more extensive. With the access to both national and global candidates, bringing about a bigger and more differentiated talent pool. This preferred standpoint is valuable not exclusively to increase competitive edge in the international market but at the same time is the key prerequisite of current working environment, where heterogeneity in team is exceptionally valued.

6. The average work load of the recruiters is considerably decreased: A part of work load is shifted on to the graduate engineer job searchers. It is their responsibility for the details and elements they post on their profile and take onus on creating their online social profile to look attractive to the employers. Some exceptionally advanced technological tools utilized in the new Hiring Strategies upgrade their proficiency significantly further. Over the internet certain administrative tasks like handling new applicants, automatic screening of qualification age and other terms, instant "fit" assessment, , aptitude based assessments, and different measurements can be performed directly on to applicants, thus bringing down the normal workload of HR .

\section{The Limitations for the Recruiters}

The new Hiring Strategies not just contain great measure of benefits and points of interest yet in addition also hold some conceivable critical impediments and disadvantages too. Even though many of the current problems can be overcome through future technological developments still a genuine contemplation is required.

\section{Excessive number is of applicants who are not}

genuine: The mind-boggling ubiquity of online networking may bring about accessibility of excessively numerous potential candidates. The limitations from the traditional strategies, which controlled such non genuine applicants, have enormously been wiped out. Today practically anyone can apply on the web, even non genuine and non-eligible candidates, prompting a strategic issue for a few smaller organizations. A large portion is of entry level candidates who dive into the employment market at the time following school graduation. But many organizations say that this quantity of unseemly non serious applicants and easily be controlled, through automated screening of applications. They acknowledge it as almost a negligible price for the general productivity and cost-adequacy of using of these new recruitment strategies.

2. Negative reputation: As compared to the ones utilizing conventional techniques, the organizations who utilize online networking as a major part of hiring strategies are in some cases seen to be less reasonable. Sometimes hasty rejection decisions results, when the candidate's information on these sites might be taken in an adverse setting and negatively by the recruiters. New Graduate engineer Job searchers likewise see this as a component of privacy infringement and think of it as unfair thereof prompting a negative picture about the organization and its HR policies.

3. Dependability and Authenticity of information: It is a general complain by both the parties that many a times the information put on the web-based social networking sites may not be extremely authentic, reliable and systematic. Verifying the exactness and credibility of this information is also a very tedious and difficult task. The information accessible on social sites may change significantly making it tough for methodical correlation between potential Job seekers.

4. Impersonal: As a noteworthy portion of the new methodologies is online a few critics and job searchers feel it has cut off the human angle from the recruitment process and has turned out to be excessively clinical. This has become all the more prominently relevant in the present times where intangible and basic factors, for example, a candidate's capability to fit in the organization and gel with the current group dynamic are crucial. To maintain a strategic distance from this the recruiter must consciously supplement these new procedures with customary balanced personal collaboration with the candidates.

5. Passive Job Seekers: Many qualified candidates might not be exceptionally motivated by the job on offer and only be passive job seekers already engaged. To have the capacity to distinguish and inspire such candidates require an extraordinary 
methodology from the Recruiters.

6. Privacy Issue: there is a big question on the privacy and security of information on these social networking sites and online recruitment may avert the new graduate job searchers and discourage them from applying for the job through these sources.

\section{The advantages for the newly graduate ESET} engineer job aspirants

1. Multiple benefits on single platform: The newly graduate job aspirant draw the advantage of the technological features of these new hiring platforms which give them multiple functions at a single search effort and save on time. The applicant not only exclusively can get to critical company information, brand, work culture, current openings or job postings but in addition also apply all at a same search attempt.

2. Open doors to International job vacancies: Internet today has provided access to information about large as well as small multinational organizations and new graduate job seekers can read and apply for job vacancies at international level.

3. Directly identified with particular key Skills: The new technically sound platforms providing special search tools have made it convenient for the job searcher to hunt for vacancies as per their desired skills and area of interest. The job searchers can also do job hunting very discreetly.

4. Less Costly: Online Registration, browsing, joining and even sending out job applications to the organization is free of cost. In fact there is no limit to the number of organizations or applications.

5. Round the clock availability: The applicants can search for jobs and apply at any time as the online application process is open round the clock.

6. Fast pivot time: new recruitment strategies are more straightforward and furthermore have altogether diminished the procedure time, therefore the applicant can have the final result in a considerably lesser time as compared to previously when conventional methods of hiring were used.

7. Increased rate of information exchange: The new recruitment strategies have made it easy to contact directly and increased the pace of information exchange between the two parties. Thus creating new level of personal alliance and each one can filter out irrelevant information.

8. Job market sensors \& advertisers: The new hiring strategies can also be utilized as job market sensors. The job aspirant and recruitment specialists both can create, keep up and mobilize their social profiles and their networks all the more viably in agreement to demands and expectations of the job market.
The Disadvantages for the Newly Graduate Engineer Job Aspirants

1. Issues of privacy: The foremost yet debatable drawback is that of privacy. Any personal information posted online, meant for family and friends can easily leak and wind up noticeably to the overall population including the employers. The novice new graduate job aspirant being new entrant into the job market may not generally realize the seriousness of the issue or fully comprehend that the information or even a casual comment enthusiastically posted online by them can be deciphered negatively by the recruiters. Companies are known to even reject applicants based on the information posted via web-based networking media, giving reasons to the presence of provocative undesirable language or unseemly pictures and information. Content like false details about qualification, skills and capabilities, poor individual habits, bad communication skills, inappropriate remarks about previous bosses, derogatory comments and remarks on organization and uncovering confidential information from a past employers are all counted as reasons behind rejections. This brings up issue of privacy rights of the job seekers as well, once it is made public. On the other hand the job aspirants contend that on many occasions the information may have been posted by others and not by themselves.

2. Issue of low personal touch: Little or no Personal involvement by the recruiters which is generally perceived as the absence of fairness in the whole selection procedure.

3. Question on authenticity; The new systems as yet don't have built up guidelines and defined policies in regards to process along these lines prompting a great deal of perplexity on their unwavering quality , reliability, genuineness and legitimacy. Recruiters are under no obligation to reveal what social networking sites were used when they came to a decision, making it easier to discriminate against candidates.

4. Short vacancy life cycle: May sometime lead to candidate's not getting opportune notifications or enough time to send out job applications.

5. The new strategies for recruitment are biased against those who do not have personal social media profiles or lack access to high end technological tools.

\section{Conclusion}

The paper provides an exploratory study of the recruitment process and the influence of Internet and social media networks stimulate, with the key point of study being the extent of evolution of recruitment strategies from traditional paper based methods to the modern e recruitment strategies. The study was done 
with the focus on two point-of-views: recruiters and newly graduate engineer job aspirants.

The worldwide dynamic business situation, rapid rate of progression of innovative techniques and stiff competition especially, have all driven the organizations to supplant existing recruitment practices. They need to adopt new hiring strategies and practices for continuous growth and development.

New hiring strategies like online recruitment utilizing Social networking platforms or mobile media are evolving as a standout among the best and effective recruitment tools. Today job fairs and Campus Recruitments are being supplemented with web-based social networking or technical contests. Today all Organizations have their own particular formal web pages and social sites, where job seekers can find out about the organisation, business, market ranking, branding, work culture \& ethics etc.

Studies have shown that India has emerged as the fourth best nation in the world in Internet utilization. Subsequently recruiters have an expansive pool from this source, from which they can look for potential candidates matching their talent requirements. .

Eventually these new hiring techniques will assume control totally and turn into the best and indispensable part of the general overall strategic decisions of the Organizations across industries. Obviously it is clear that the new hiring strategies have prompted inevitable change in the recruitment procedure, yet their effect upon the far reaching practices and standards of HR and work force administration are not completely defined. In the current scenario, it appears as though the essential change has been an innovative one, in which the daily paper help-needed advertisements and snail-paced paper resume of the past have been flawlessly supplanted with their electronic successors but it not be quite as it appears if scrutinized carefully.

At the end of the day, in spite of the fact that the recruitment tools we utilize, for Talent searching, have changed, yet the greater percentage of the underlining principles that oversee the hiring strategies have remained essentially unaltered. Today the HR professionals have been presented with a unique and impressive opportunity to usher and introduce a new paradigm which is a combination of the best of two worlds - the proficiency and unparalleled reach of the Internet with the high touch (defining very close and personal relationship with prospective and talented candidates), natural, and exceedingly human concentration of conventional recruitment techniques.

Technology has been and will keep on being a vital factor in this procedure, however we should remember that it is a just a tool, instead of an end unto itself. Our all-encompassing objective stays unaltered. The recruitment experts, we are entrusted with the responsibility of finding and retaining the best talent right from the entry level. Recruitment using new techniques ought to be viewed as only one of the numerous strategies we use to accomplish this objective - no more and no less.

Some recruiters even today abstain from using social media as a tool for recruitment. They do not fully comprehend the advantage of the benefits and opportunities that new recruitment channels like social media offer to the recruitment process.

\section{Recommendations}

1. The new recruitment strategies are the present and the future of recruitment and are here to stay. However some aspects of old methods of hiring like personal connection between recruiters and aspirants, will continue to exist.

2. Despite numerous advantages the new recruitment strategies are not impeccable and certain particular job profiles can't be filled by utilizing these by themselves. For a more meaning full recruitment task they must be augmented with other more established recruitment techniques.

3. Internet gives freedom of space and both the recruiter and the new graduate engineer job searchers can use this fact to their advantage, Long depictions can be utilized for job posting, branding, work culture, promotions as well as candidate profiles including image and even multimedia resumes as profiles.

4. The new techniques of recruitment are exceptionally successful in branding and building a positive picture of the organization among the young aspirants. Hence it becomes even more important for both the stakeholders that the information being presented is precisely scrutinized and investigated before publishing.

5. It was discovered that people are spending large portion (almost 30\%) of their online time on Social networking media. This can provide the opportunity to the recruiter to utilize this reality for roping individuals having specialty or particular niche skills combined with extensive persuasion. The new graduate engineer job aspirants too react positively to the opportunities offered to them through webbased social networking.

6. Cultural differences should be given due consideration as well because this difference can influence the aspirants choice of Job search channel. Issues like ethics, fairness, reasonableness and legal aspects should likewise be also considered in detail.

\section{Acknowledgement}

This paper is acknowledged under the Integral University Manuscript No: IU/R\&D/2018-MCN000262

\section{References}

1. Alfus, P. (2000) 'Today's Recruitment Practices Require Traditional and Internet Techniques', Hotel and Motel Management, December

2. Baillie, J. (1996) 'Attracting Employees Who Surf the Internet', People Management, 2:17, 46-7. 
3. Bartram, D. (2005) 'Testing on the Internet: Issues, Challenges and Opprtunities in the Field of Occupational Assessment', in Bartram, D. and Hambleton, R.(eds),

4. Bartram, D. (2000) 'Internet Recruitment and Selection: Kissing Frogs to Find Princes', International Journal of Selection and Assessment, 8:4,261-74.

5. Bingham, B., Ilg, S. and Davidson, N. (2002), 'Great Candidates Fast: On-Line Job Application and Electronic Processing: Washington State's New Internet Application System', Public Personnel Management, 31:1, 53-64.

6. Cober, R.T., Brown, D.J., Blumenthal, A.J., Doverspike, D. and Levy, P. (2000) 'The Quest for the Qualified Job Surfer: It's Time the Public Sector Catches the Wave'.

7. Davison, H., Maraist, C. and Bing, M. (2011) 'Friend or foe? The promise and pitfalls of using social networking sites for HR decisions', Journal of Business Psychology. Vol.26, Issue 2: pp.153-9.

8. Davison, H., Maraist, C., Hamilton, R. and Bing, M. (2012) 'To screen or not to screen/ Using the internet for selection decisions', Employee Responsibilities and Rights Journal, Vol.24, Issue 1: pp.1-21.

9. Feldman, D.C. and Klaas, B.S. (2002) 'Internet Job Hunting: A Field Study of Applicant Experiences with On-Line Recruiting', Human Resource Management, 41:2,175-92.

10. Freeman, R.B. (2002) 'The Labour Market in the New Information Economy', Oxford Review of Economic Policy, 18:3, 288-305.

11. Galanaki, E. (2002) 'The Decision to Recruit Online: A Descriptive Study', Career Development International, $7: 4,243-51$

12. IRS Employment Review (2005) 'Online Recruitment in the UK: 10 Years Older and Wiser', IRS Employment Review, 822, [online] (cited 19 June 2017) Available from

http://www.irsemploymentreview.com/DisplayArticle.asp ?ArticleID $=52687$

13. Jobvite (2012) 'The Jobvite 2012 Social Recruiting Survey Results', Jobvite, BurlingameJobvite.com. http://web.jobvite.com/rs/jobvite/images/Jobvite_2012_S ocial_Recruiting_Survey.pdf?mkt_tok=3RkMMJWWfF9 wsRokvqvBZKXonjHpfsX86OgoUaKwlMI\%2F0ER3f OvrPUfGjI4CSMdkI\%2FqLAzICFpZo2FFSFeKDdZRF

14. Joos, J.G. (2008) 'Social media: New frontiers in hiring and recruiting', Employment Relations Today, Vol. 35, Issue 1: pp.51-59.

15. Kinder, T. (2000) 'The Use of the Internet in Recruitment: Case Studies from West Lothian, Scotland', Technovation, 20:9, 461-475.

16. Kuhn, P.J. (2003) 'The Internet and Matching in Labor Markets', in Jones, D.C. (ed) New Economy Handbook, Academic Press, Amsterdam, [online] (cited 15 May 2016) Available from

http://www.econ.ucsb.edu/ pjkuhn/Research\%20Papers/ Handbook.pdf

17. International Journal of Selection and Assessment, 8:4, 261-274, [online] (cited 10 June 2017) Available from http://www.nielsen-netratings.com/hof_off.htm
18. Lievens, F., Dam, K.v. and Anderson, N. (2002) 'Recent Trends and Challenges in Personnel Selection', Personnel Review, 31:5,580-601.

19. Madera, M. J. (2012). Using social networking websites as a selection tool: The role of selection process fairness and job pursuit intentions. International Journal of Hospitality Management, 31, pp. 1276-82.

20. McDougall, B. (2002) 'Cyber-Recruitment: The Rise of the E-Labour Market and Its Implications for the Federal Public Service', [online] (cited 25 May 2016) Available from http://www.rma-agrh.gc.ca/research/labourmarket/e-recruitment_e.pdf

21. Mohamed, A.A., Orife, J.N., and Wibowo, K. (2002) 'The Legality of Key Word Search as a Personnel Selection Tool', Employee Relations, 24:5,516-22.

22. Pin, R.J., Laorden, M. and Sáenz-Diez, I. (2001) 'Internet Recruiting Power: Opportunities and Effectiveness', IESE Research Papers D/439, [online] (cited 25 May 2016) Available from http://www.iese.edu/research/pdfs/DI-0439-E.pdf

23. Piturro, M. (2000) 'The Power of E-Cruiting', Management Review, 89:1,33-7.

24. Salmen, S. (2012). Einleitung - Die Suche von TopMitarbeitern im War for Talent! In B. Rath, \& S. Salmen, Recruiting in Social Web (pp. 30-40). Göttingen: BusinessVillage GmbH.

25. Salmen, S. (2012). What's Next - Die nächsten Trends. In B. H. Rath, \& S. Salmen, Recruiting im Social Web (p. 284). Göttingen: Business Village GmbH.

26. Sarkar, A., Kumar, S. (2007). Effective Recruitment and Selection: An approach towards model building. HRM Review, 7 (7), pp. 15-22.

27. Schreyer, R. and J. McCarter, J. (1998) The Employer's Guide to Recruiting on the Internet, Impact Publications, Manassas Park, VA

28. Sinha and Thaley. (2013). 'A Review On Changing Trend Of Recruitment Practice To Enhance The Quality Of Hiring In Global Organizations.' Journal of Contemporary Management Issues, Prosinac 2013, Vol. 18 No. 2,. pp. 141-56.

29. Tarique, I. and Schuler, R.S. (2010), “Global talent management: literature review, integrative framework, and suggestions for further research", Journal of World Business, Vol. 45 No. 2, pp. 122-33.

30. Veger, M. (2006) 'How Does Internet Recruitment Have Effect on Recruitment Performance?' Fourth Twente Student Conference on IT, 30 January, Enschede, [online] (cited 31 May 2016) Available from http://referaat.cs.utwente.nl/documents/2006_04_DTechnology_organization_and_Innovation/2006_04_D_V eger,M.-

How_does_Internet_recruitment_have_effect_on_recruit ment_performance.pdf

31. Vyas, Ajayraj M. (2011). Human Resource Recruitment in India: Critical Role of Online Recruitment System, 1 (6), pp. 1-4.

32. Zielinski, D. (2012) Find social media's value, HR Magazine, $1^{\text {st }}$ August 2012.

\section{Appendix 1: Traditional verses New Hiring strategies}

\begin{tabular}{|l|l|l|}
\hline S. No & Traditional Recruitment Techniques & New Recruitment Strategies \\
\hline 01 & $\begin{array}{l}\text { Newspapers Adverts: Oldest means of } \\
\text { communicating about Job vacancies. Still } \\
\text { popular with the HRs of some organizations in } \\
\text { the developing economies like India. }\end{array}$ & $\begin{array}{l}\text { Online Job Portals: Internet websites like } \\
\text { monster.com, naukri.com. \& Timesjobs.com etc. } \\
\text { are considerably popular with both the Fresh } \\
\text { Graduate Engineer job aspirants as well as the } \\
\text { Recruiters. }\end{array}$ \\
\hline
\end{tabular}




\begin{tabular}{|c|c|c|}
\hline 02 & $\begin{array}{l}\text { State Run Employment Offices: functioning } \\
\text { on local level database they are / were used for } \\
\text { sourcing people. }\end{array}$ & $\begin{array}{l}\text { Social Media: Facebook and Twitter have } \\
\text { emerged as new source of talent pool because of } \\
\text { their popularity with the present generation. }\end{array}$ \\
\hline 03 & $\begin{array}{l}\text { Internal or lateral Hiring: among the easiest } \\
\text { and time tested methods where the capabilities } \\
\text { and performance level of existing employees is } \\
\text { already known. Considered very positive in } \\
\text { building long term commitment from existing } \\
\text { employees. }\end{array}$ & $\begin{array}{l}\text { Smart Phones: even though a small gadget they } \\
\text { have literally given the whole internet in the } \\
\text { hands of today's generation Recruiters are using } \\
\text { this technology to their advantage to allure the } \\
\text { potential candidates by sharing company / job } \\
\text { details but also to communicate through SMS } \\
\text { thus optimizing company's portal }\end{array}$ \\
\hline 04 & $\begin{array}{l}\text { Private Employment Agencies: used for } \\
\text { outsourcing and hiring candidates. The } \\
\text { company HR saved on time on the initial } \\
\text { screening and short listing of suitable } \\
\text { candidates matching the company / job } \\
\text { requirements. }\end{array}$ & $\begin{array}{l}\text { Coding / Technical contests: This is one of the } \\
\text { most recent hiring strategies, specially being } \\
\text { used by the IT companies to screen the } \\
\text { candidates on their technical skills. }\end{array}$ \\
\hline 05 & $\begin{array}{l}\text { Campus Hiring: Educational institution were } \\
\text { visited for the hiring process, with the objective } \\
\text { to pick up talented and qualified candidates } \\
\text { before they complete their education and } \\
\text { providing job opportunity to students pursuing } \\
\text { or on the verge of completion of their enrolled } \\
\text { course. Campus Placement continues to be } \\
\text { quite a popular recruitment strategy with both } \\
\text { the parties seekers }\end{array}$ & $\begin{array}{l}\text { Live projects for screening: Another new hiring } \\
\text { technique being started by some organizations. } \\
\text { Here the job aspirants are given an actual tasks or } \\
\text { projects instead of doing a screening interview. } \\
\text { The assigned task has to be completed within a } \\
\text { stipulated time and then the output is tested. } \\
\text { Candidates who triggered the maximum output } \\
\text { are selected for further rounds of interviews. It is } \\
\text { considered as one of the best ways to seek as } \\
\text { insight into the candidate seriousness and } \\
\text { performance levels. }\end{array}$ \\
\hline \multirow[t]{2}{*}{06} & $\begin{array}{l}\text { Employee Referrals: recognized as a cost } \\
\text { effective method where existing employees are } \\
\text { encouraged to identify and recommend new } \\
\text { potential candidates from their personal and } \\
\text { social networks to join the workforce of the } \\
\text { company. They are rewarded with a referral } \\
\text { Incentive and sometimes even linked to } \\
\text { appraisal systems. Used mostly to build upon } \\
\text { the volume of fresh graduate engineer recruits. }\end{array}$ & $\begin{array}{l}\text { Volunteering: An interesting hiring strategy } \\
\text { being used now, here young college students are } \\
\text { invited to not only have a hands on and try a new } \\
\text { products but they are also encouraged to promote } \\
\text { the product among their peer groups. Initially the } \\
\text { student is rewarded with free trial and access to } \\
\text { new gadgets. Gradually those students who } \\
\text { exhibit a flair and seriousness towards the } \\
\text { products are recommended for absorption in the } \\
\text { company. }\end{array}$ \\
\hline & & $\begin{array}{l}\text { Event Recruitment: A relatively new and useful } \\
\text { hiring strategy is sponsoring events for building } \\
\text { brand value. Companies sponsor events that are } \\
\text { related to their ethic value, which they wish to } \\
\text { represent through such association. The purpose } \\
\text { is to gain popularity among new generation job } \\
\text { seekers. }\end{array}$ \\
\hline
\end{tabular}

Appendix 2: Details of respondents

\begin{tabular}{|l|l|l|c|c|}
\hline \multicolumn{1}{|c|}{ Company Name } & Location & Industrial Sector & Recruiters & $\begin{array}{c}\text { Number of Newly } \\
\text { Graduate Engineer } \\
\text { Job Aspirants } \\
\text { applied or selected) }\end{array}$ \\
\hline $\begin{array}{l}\text { TATA Consultancy Services } \\
\text { (TCS ) }\end{array}$ & Lucknow & $\begin{array}{l}\text { Information } \\
\text { Technology }\end{array}$ & 20 & 20 \\
\hline ZTE & Lucknow & $\begin{array}{l}\text { Electronics \& } \\
\text { Communication }\end{array}$ & 20 & 20 \\
\hline $\begin{array}{l}\text { American Towers } \\
\text { Corporation Pvt Ltd }\end{array}$ & Noida & $\begin{array}{l}\text { Electronics } \\
\text { Infrastructure }\end{array}$ & 15 & 20 \\
\hline A Automovers Pvt Ltd & Allahabad & $\begin{array}{l}\text { Automobiles/ } \\
\text { Mechanical }\end{array}$ & 10 & 10 \\
\hline
\end{tabular}




\begin{tabular}{|l|l|l|c|c|}
\hline $\begin{array}{l}\text { Pioneer Machines \& } \\
\text { Automations (P) Ltd. }\end{array}$ & Ghaziabad & Electrical Appliances & 10 & 10 \\
\hline Raheja Group & Noida & Civil / Construction & 15 & 10 \\
\hline $\begin{array}{l}\text { Uttam Industrial Engineering } \\
\text { Ltd, }\end{array}$ & Ghaziabad & $\begin{array}{l}\text { Manufacturing / } \\
\text { Mechanical }\end{array}$ & 10 & 10 \\
\hline Total & & & 100 & 100 \\
\hline
\end{tabular}

Responses: Recruiters Perspective

Which of the following according to you is the most effective way of Recruitment

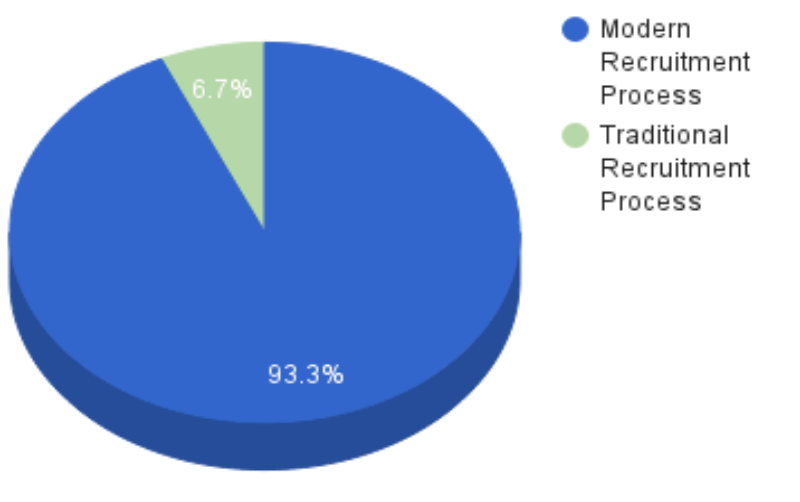

Fig. 1: The most effective way of Recruitment

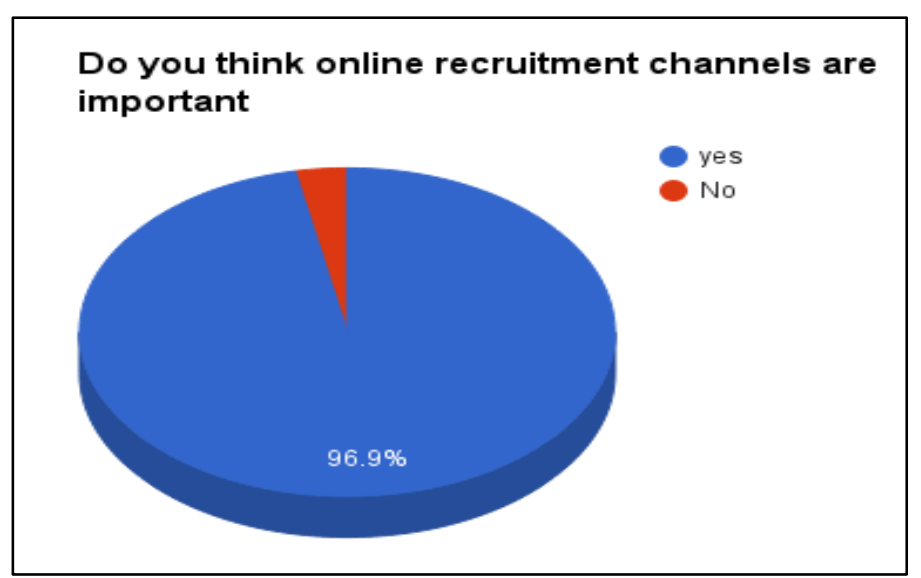

Fig. 2: Online Recruitment Methods are important

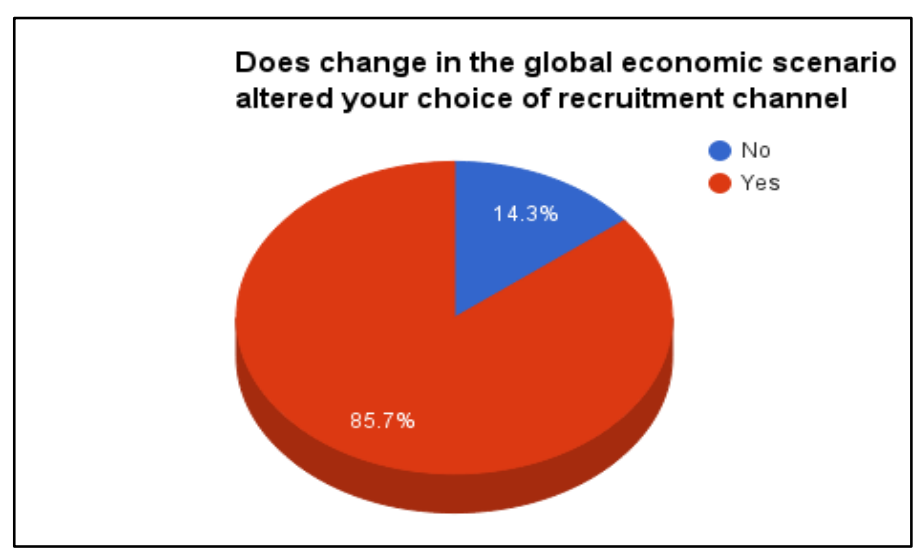

Fig. 3: Change in the economic scenario altered the choice of recruitment channel 


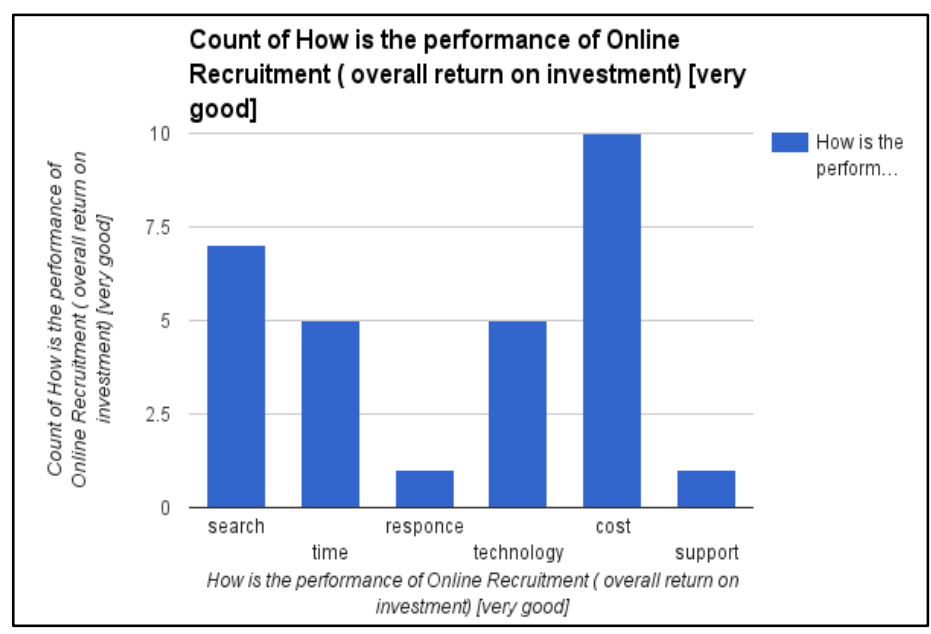

Fig. 4: The performance of online recruitment (overall return on investment)

Responses: Fresh Graduate Engineer Job seeker's Perspective:

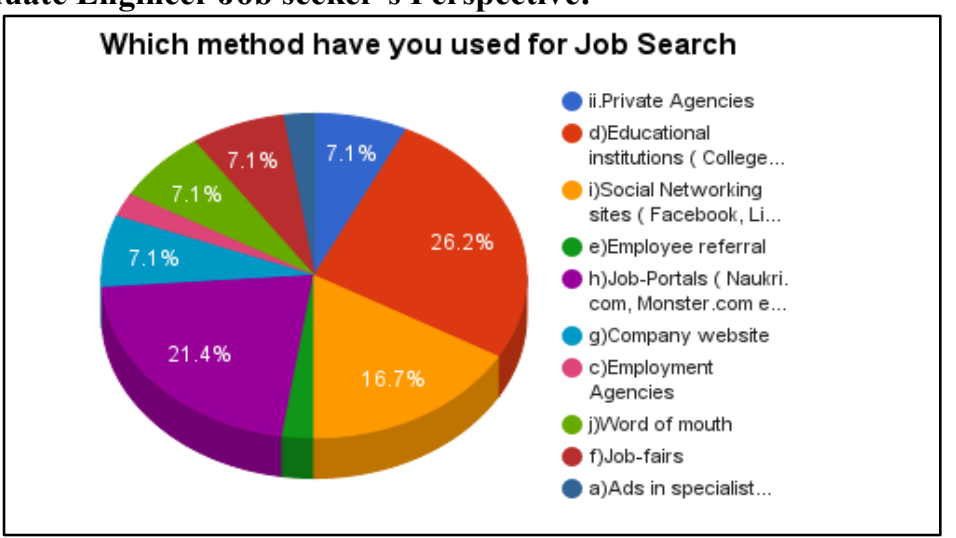

Fig. 5: Different methods used for Job Search

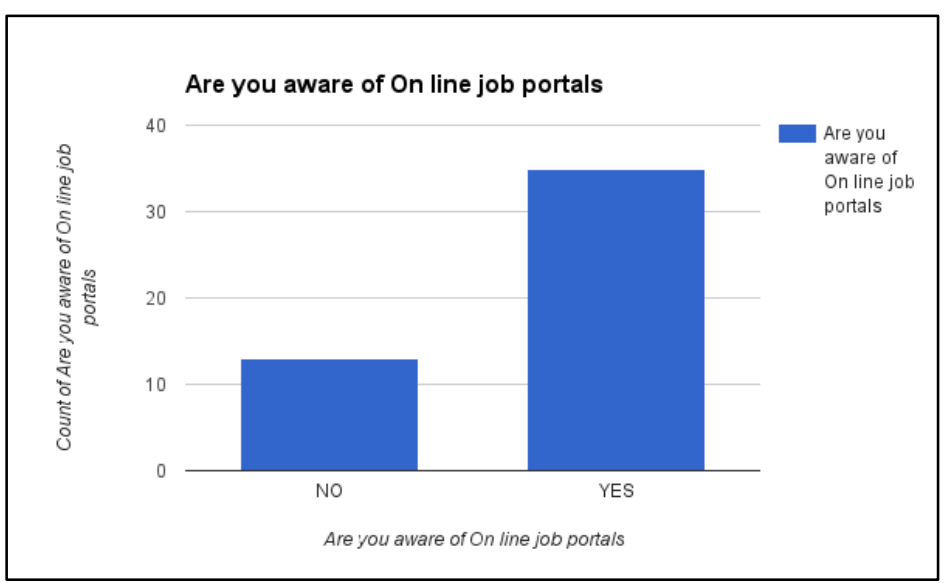

Fig. 6: Awareness of online job portals 


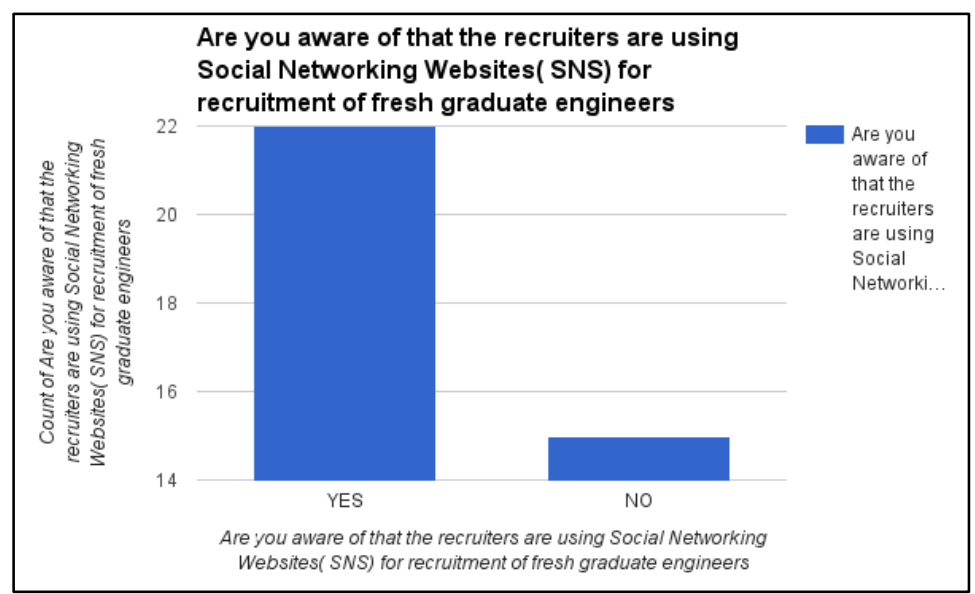

Fig. 7: Awareness of recruiters hiring through social media

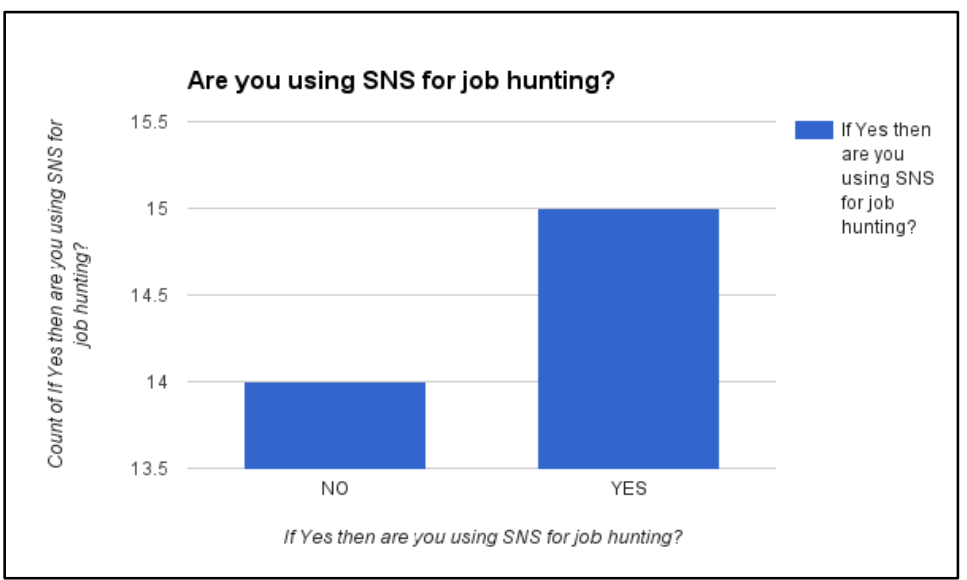

Fig. 8: use of Social Media for job hunting

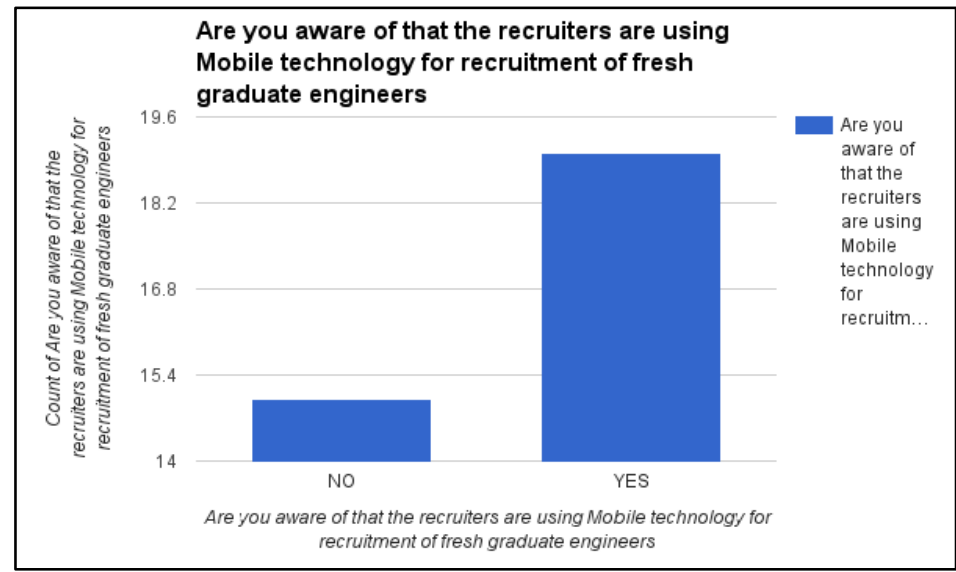

Fig. 9: Use of mobile technology for job hunting 